\title{
DESENVOLVIMENTO TERRITORIAL E GÊNERO: A MULHER COMO AGENTE DE MUDANÇA SOCIAL EM MOÇAMBIQUE
}

\author{
Gabriela de Azevedo Marques ${ }^{1}$ \\ Francileuda Pontes Paz ${ }^{2}$
}

\begin{abstract}
Resumo
Neste artigo, busca-se compreender de que maneira a mulher se constitui em um agente de mudança social para o desenvolvimento territorial em Moçambique. Para isto, discute-se o desenvolvimento com ênfase na abordagem territorial; são apresentados dados secundários socioeconômicos de Moçambique, com diferenciação de resultados entre homens e mulheres, e de dados específicos sobre as mulheres; e realiza-se descrição e análise do xitike enquanto prática emancipatória feminina. Como resultado principal da pesquisa, observou-se que, no contexto da mulher moçambicana, a prática do xitike tem contribuído com a expansão das suas capacidades e ampliação das suas possibilidades de vida. Ao observar a questão do gênero, a perspectiva territorial auxilia a ampliar, portanto, a reflexão sobre o desenvolvimento.
\end{abstract}

Palavras-chave: gênero. desenvolvimento territorial. xitike.

\section{TERRITORIAL DEVELOPMENT AND GENDER: THE WOMAN AS AGENT OF SOCIAL CHANGE IN MOZAMBIQUE}

\begin{abstract}
This article seeks to understand how women take form as agents of social change to the territorial development in Mozambique. For this purpose, a discussion on the issue of the development will be made, emphasizing the territorial approach; Mozambique's socio economic data and data regarding the matter of gender will be presented; and also a description and analysis of the xitike as a female emancipatory practice will be made. The main result is that in Mozambique's context, the xitike practice has contributed to the expansion of women's skills and possibilities of living. In the observation of the gender matter, the territorial approach helps to broaden the reflection on development.
\end{abstract}

Keywords: gender. territorial development. xitike.

1 Graduada em Arquitetura e Urbanismo pela Universidade Federal do Ceará (UFC). E-mail: gabrieladamarques@gmail.com

2 Mestranda em Geografia pela Universidade Federal do Ceará (UFC), integrante do Laboratório de Planejamento Urbano e Regional (LAPUR) e graduada em Geografia/Licenciatura pela Universidade Estadual do Ceará (2018). E-mail: leudapontes@gmail.com 


\section{DESARROLLO TERRITORIAL Y GÉNERO: LA MUJER COMO AGENTE DE CAMBIO SOCIAL EN MOZAMBIQUE}

\section{Resumen}

En este artículo se busca comprender cómo la mujer se constituye en un agente de cambio social para el desarrollo territorial de Mozambique. Con este fín, se discute el desarrollo con énfasis en el abordaje territorial; datos secundarios socioeconómicos de Mozambique serán presentados, con diferenciación entre hombres y mujeres, así como datos específicos de las mujeres; y se realizará una descripción y análisis del xitike como práctica emancipadora femenina. El resultado es que en el contexto mozambicano, el xitike contribuye con la ampliación de las capacidades, habilidades y posibilidades de vida de la mujer. Observando el tema del género, el abordaje territorial ayuda a ampliar la reflexión sobre el desarrollo.

Palabras clave: género. desarrollo territorial. xitike.

\section{INTRODUÇÃO}

A perspectiva do desenvolvimento territorial tem trazido novas abordagens à questão desenvolvimentista, colocando em evidência os sujeitos sociais e suas práticas. Dentro desta abordagem, a questão do gênero se coloca como um importante aspecto, ao compreendermos que uma condição mais igualitária entre homens e mulheres é capaz de construir um desenvolvimento não apenas destas mulheres, mas da sociedade como um todo. Este trabalho busca refletir acerca do desenvolvimento vinculado ao conceito de território, através da valorização da mulher como agente de mudança social. (SEN, 1999; BANCO MUNDIAL, 2012)

Dentro do contexto socioespacial de Moçambique, que se configura como um dos países com menor Índice de Desenvolvimento Humano (IDH) do mundo, com altos índices de desemprego e pobreza, busca-se realizar uma aproximação com a realidade feminina, dentro da qual os dados sobre gênero e a literatura revelam uma grande dificuldade da mulher de se libertar da posição subalterna que tem em relação ao homem.

Através de uma exploração metodológica-investigativa em busca de costumes e práticas sociais próprias das mulheres moçambicanas, a pesquisa se aproxima do xitike, um costume muito encontrado em pequenos grupos de moçambicanos e moçambicanas, e que é especialmente forte entre as mulheres. $O$ trabalho traz a reflexão sobre o quanto esta prática traz benefícios às vidas dessas mulheres, e de que forma estes benefícios pontuais geram benefícios mais amplos à sociedade em diversas escalas, contribuindo, assim, para o desenvolvimento territorial. 
$\mathrm{O}$ artigo tem, portanto, como objetivo geral, compreender de que forma a mulher se constitui em um agente de mudança social para o desenvolvimento territorial em Moçambique. Os objetivos específicos são: investigar o caminho da construção do paradigma do desenvolvimento territorial; relacionar a visão do desenvolvimento territorial à do desenvolvimento como liberdade, examinando de que forma estes pontos de vista consideram as questões de gênero; e, a partir da aproximação com o espaço geográfico moçambicano, identificar fatores culturais e socioeconômicos que fortalecem a mulher moçambicana enquanto agente de mudança social capaz de proporcionar desenvolvimento, dentre os quais delineou-se a prática do xitike.

Metodologicamente, seguiu-se as seguintes etapas: realização de levantamento bibliográfico a respeito da temática do desenvolvimento e do conceito de território; coleta de dados socioeconômicos de Moçambique, com diferenciação de resultados entre homens e mulheres, e de dados específicos sobre as mulheres, através de dados sistematizados pelo Instituto Nacional de Estatística de Moçambique (INE, 2017), Fundo de População das Nações Unidas (UNFPA, 2017) e Organização das Nações Unidas para a Educação, Ciência e Cultura (UNESCO, 2016); e análise do xitike enquanto prática emancipatória feminina, a partir de trabalhos que abordam essa prática.

Assim, o texto é composto por quatro partes principais. Inicialmente, estrutura-se uma discussão teórico-conceitual a respeito do desenvolvimento; em seguida, apresenta-se um panorama populacional e socioeconômico de Moçambique e de questões relativas ao gênero; posteriormente, a discussão é conduzida para a visão seniana do desenvolvimento como liberdade, e especificamente o seu ponto de vista sobre o conceito de agente de mudança social, ao qual é relacionado à mulher moçambicana. Neste mesmo ponto, se retorna ao território moçambicano, através de um estudo mais aprofundado sobre o xitike. Por fim, no último tópico, algumas conclusões são apresentadas sobre os pontos apresentados e algumas questões para discussão são levantadas.

\section{Desenvolvimento territorial: percursos teóricos}

A temática do desenvolvimento é bastante trabalhada nas ciências sociais, em especial na Economia, nas Políticas Públicas e na Geografia. No entanto, o conceito de desenvolvimento surge na ciência biológica com os trabalhos de Darwin, indicando um processo de evolução dos seres vivos para um estágio mais avançado da genética (SANTOS et al, 2012). Contudo, a ideia de desenvolvimento tem origem muito antes da segunda metade do século XIX, remontando à 
própria origem do sistema mundial capitalista e deve ser entendida como parte intrínseca da visão de progresso, segundo Prado (2016).

Inicialmente, os estudos sobre o desenvolvimento dispunham de um caráter economicista e sua compreensão estava atrelada à noção de progresso técnico-científico de uma nação, mais especificamente ligada ao crescimento econômico. Deste modo, as análises eram realizadas levando em consideração o aumento da riqueza, que era medida a partir do Produto Interno Bruto (PIB) de um país. Mas, em meados do século XX, o desenvolvimento se torna pauta central nas discussões não somente econômicas, mas também sociais e ambientais, que passam a obter uma redefinição do conceito.

Essa mudança de paradigma resulta de novos debates sobre o crescimento da pobreza, das desigualdades sociais e da degradação do meio ambiente, resultante, também, do padrão de produção e consumo empregado até aquele período.

\begin{abstract}
Le concept de développement, en intégrant le social et l'humain, subit une véritable révolution sémantique. Au développement tout court confiné dans le contenu sémantique exclusivement économique qui le simplifiait outrancièrement, on associera désormais des épithètes qui témoignent «du droit à l'expression des valeurs culturelles des civilisations issues de l'histoire et des situations sociales spécifiques des sociétés émergentes». Ainsi, à la notion de self-reliance, d'autonomie ou développement autocentré qui fit son entrée dans la littérature du développement, se succèdent les concepts de développement endogène, développement solidaire, communautaire, intégré, authentique, autonome et populaire, durable, humain, harmonisé, participatif, global, l'écodéveloppement, l'endo-développement, l'ethnodéveloppement et pour finir, le développement socialiste. (LEGOUTÉ, 2001. p. 18)
\end{abstract}

O desenvolvimento pensado exclusivamente pela renda per capita, com o viés puramente econômico, pouco havia contribuído para pensar políticas sociais que versassem os problemas socioambientais, os quais passaram a ser enfatizados nas conferências mundiais do clima e da erradicação da pobreza. Nesse sentido, tornou-se imperioso tratar o desenvolvimento de um país dentro da perspectiva da qualidade e melhoria de vida, tendo, assim, como alvo central os atores sociais.

Com o conjunto de novas demandas a respeito da discussão sobre o desenvolvimento, a ciência geográfica passou a contribuir nos debates de forma a discutir o desenvolvimento atrelado a outros termos, tais como: sustentabilidade, endogenia e território. Interessa-nos este último como categoria de análise para entender a relação mulher-desenvolvimento territorial em Moçambique. Por conseguinte, se parte do pressuposto de que o vivido se dá no território sinônimo de espaço humano, habitado e apropriado (SANTOS, 1998) - e é a partir deste que se dão as relações sociais de poder, de inclusão e de exclusão dos atores sociais. 
Segundo Moura e Moreira (2014, p. 64), “a ideia de território pode igualmente ser concebida como "uma arena de influência", arena de ação e gestão do local onde se confrontam e enfrentam-se os atores implicados na sua estruturação". Logo, é necessário diferenciar os diversos territórios e seus processos, dado que eles são constituídos segundo seus sujeitos sociais (HAESBAERT, 2004).

A leitura do desenvolvimento pelo território dá subsídio para se evidenciar as territorialidades que se estabelecem através das relações socioculturais de uma determinada localidade. Torna possível apontar as práticas endógenas que contribuem para o desenvolvimento, em um momento em que se almeja pensar o desenvolvimento a partir das capacidades locais e individuais.

A abordagem territorialista do desenvolvimento ganha destaque a partir dos anos 1970, dadas as experiências europeias e norte-americanas que reforçaram "a ideia de que o desenvolvimento de um espaço depende parcialmente do nível de organização de sua sociedade em relação aos objetivos que lhes são comuns" (CORRÊA, 2009. p. 24).

Conforme Pires (2007), o desenvolvimento territorial pode ser compreendido como

um processo de mudança social de caráter endógeno, capaz de produzir solidariedade e cidadania comunitária, e de conduzir de forma integrada e permanente a mudança qualitativa e a melhoria do bem-estar da população de uma localidade ou de uma região. O processo de desenvolvimento territorial é dinamizado por expectativas de agentes locais/regionais, nas quais o território seria o agente/ator principal do desenvolvimento, e as políticas públicas, as instituições, as organizações e as governanças seriam os recursos específicos, a um só tempo disponível e a serem criados (inventados e/ou inovados) no local ou região, ou nos mais diversos elos da rede mundial. (PIRES 2007, p. 159).

Jean (2015) afirma que

le concept de développement territorial propose bien plus qu'une autre manière de rendre intelligible développement régional et local à différents échelles. Il s'agit d'un changement paradigmatique dans les études en développement régional. Avec notion de développement territorial, les sciences sociales, dans une perspective multidisciplinaire et interdisciplinaire, be connaissance territoire, non seulement comme une réalité biophysique bien tangible, plus aussi comme une construction sociale. (JEAN, 2015. p. 118)

Desse modo, o desenvolvimento não se define com uma conceituação linear e mecânica da qual leva em consideração a espacialização da modernização capitalista e o crescimento econômico. Contrariamente, trata-se de levar em consideração as contingências da trajetória histórica e as múltiplas alternativas que podem ser construídas pelos sujeitos (BRANDÃO, 2008). Nesse sentido, a dimensão escalar adquire importância, pois colabora, 
metodologicamente, para a apreensão do processo que se deseja compreender. Por conseguinte, a leitura escalar do desenvolvimento territorial de Moçambique contribui para uma apreensão da totalidade que se configura do local ao nacional.

O território moçambicano é peculiar em sua formação social, histórica, econômica e cultural. Do ponto de vista histórico e estrutural, vale lembrar que Moçambique conquistou a sua independência em junho de 1975, no entanto, o país esteve em guerra civil na década seguinte (1982-1992). Este fator se mostra preponderante para entender o cenário de desigualdades e as diversas privações que a população moçambicana enfrenta.

Nesse contexto geral de restrições está a figura feminina, que se configura como um dos principais atores afetados por um conjunto de obstáculos constituído pela falta de acesso às infraestruturas sociais e pela dificuldade de se emancipar. Contraditoriamente, a mulher cumpre um papel essencial na estabilidade do núcleo familiar e, por consequência, da comunidade em que se relaciona. Com isto, corrobora-se o aspecto ativo da mulher, assim como se reforça a importância de pensar as ações femininas na construção do desenvolvimento territorial.

\section{MOÇAMBIQUE: A SOCIEDADE E A MULHER}

\section{Dados gerais sobre Moçambique}

A República de Moçambique está localizada na costa sudeste do continente africano e ocupa uma área de $799.380 \mathrm{Km}^{2}$, constituída por dez províncias e uma capital: Niassa, Cabo Delgado, Tete, Zambézia, Nampula, Manica, Sofala, Inhambane, Gaza, Maputo e a Cidade de Maputo (Figura 1).

Estima-se que o país possui 27.909.798 habitantes, com predominância da população feminina em comparação com a masculina, correspondendo às porcentagens de 52,17\% e 47,82\% respectivamente. Pontua-se, ainda, uma elevada densidade demográfica na Cidade de Maputo - capital do país, com $3.671 \mathrm{Hab} / \mathrm{Km}^{2}$ (INE, 2017). Este fenômeno se justifica pela quantidade de infraestruturas e de serviços concentrados na capital, que também é sede administrativa do governo central. Contudo, Moçambique mostra-se ainda predominantemente rural, com a maioria da população residindo no campo.

Segundo o UNFPA (2017), o crescimento econômico real do país, desde 1996, tem sido sempre superior a 5\%, conseguindo por vezes alcançar $10 \%$. Este elevado crescimento 
econômico tem sido acompanhado por um considerável crescimento populacional e uma relativa melhoria nos índices de PIB e PIB per capita. No entanto, é notável que os índices

Figura 1: Mapa de localização de Moçambique

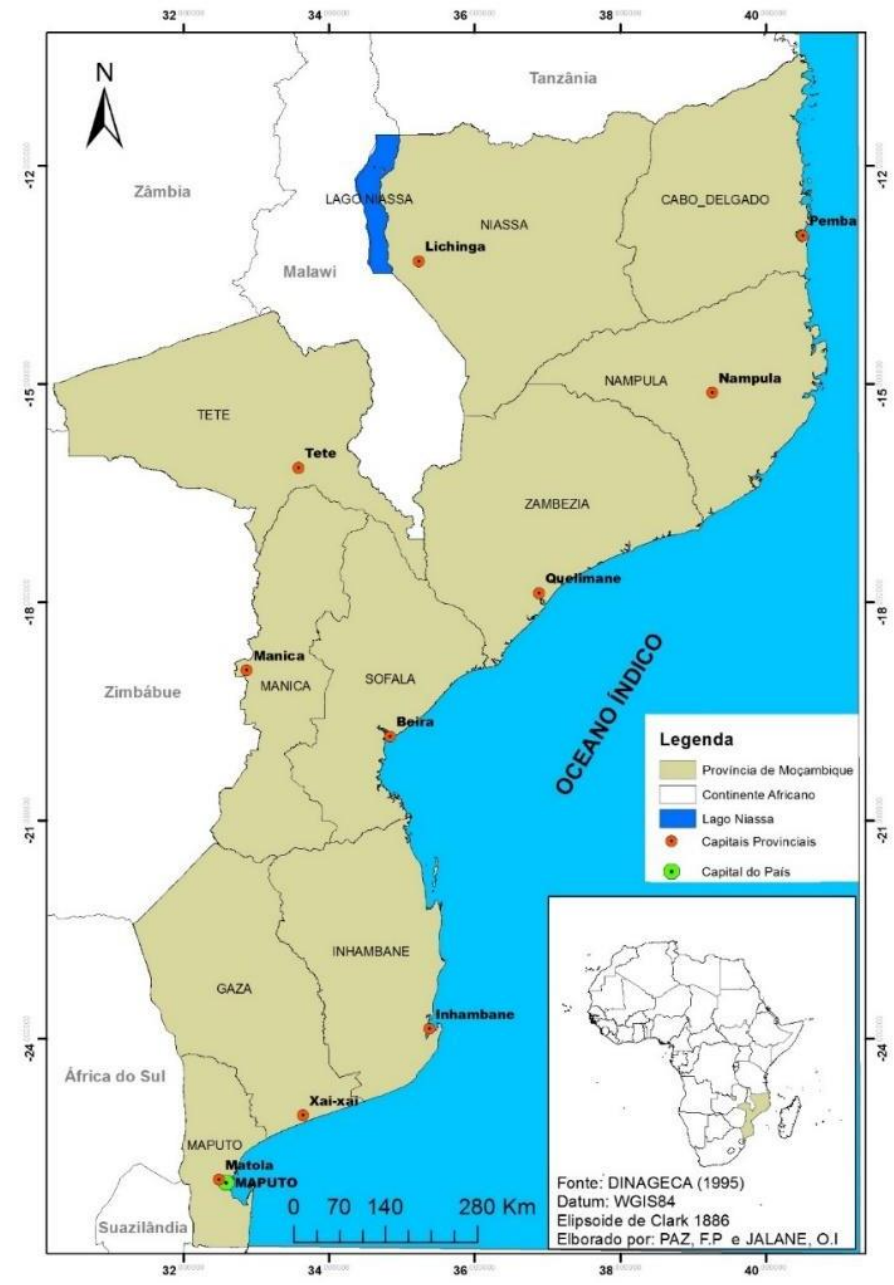

Fonte: Elaborado por PAZ, F. P e JALANE, O. I (2018).

socioeconômicos e relativos à pobreza não foram reduzidos, o que tem ocasionado a manutenção de uma grande e preocupante desigualdade social. Em 2015, por exemplo, estimava-se que $46 \%$ da população moçambicana ainda estava condicionada à extrema pobreza. (UNFPA, 2017)

É importante apontar que Moçambique possui muitas especificidades e desigualdades regionais. Assim, os dados apresentados variam bastante entre sua região norte, predominantemente rural, e a região sul, mais urbanizada e concentradora de maior número de infraestruturas e de melhores índices socioeconômicos. Autores defendem que a maior conexão da capital do país com o mundo globalizado traz à região sul do país melhores condições de emprego e renda, escolaridade e saúde; enquanto o norte permanece em uma situação de atraso 
e esquecimento até os dias de hoje. É também a região norte que concentra grande parte da população em situação de extrema pobreza do país. (TVEDEN et al, 2010)

Já em relação ao Índice de Desenvolvimento Humano (IDH) do país, este se encontra, no ano de 2017 , em $181^{\circ}$ lugar entre os 188 países analisados. É importante destacar que o IDH das mulheres moçambicanas (0.39) é, ainda, consideravelmente inferior ao dos homens (0.44), revelando uma grande disparidade entre as qualidades de vida masculina e feminina. (UNFPA, 2017)

As altas taxas de desemprego (24,5\%, em 2017) do país são constantes, revelando que o crescimento do PIB não tem ocasionado melhoras na situação de trabalho da população moçambicana. O desemprego é especialmente alto entre os jovens (40\%), fato bastante preocupante ao constatarmos que, ainda segundo dados da UNFPA (2017), quase metade da população do país (45\%) é constituída por pessoas com menos de 15 anos de idade.

\section{Um panorama sobre o gênero feminino em Moçambique}

Na Constituição de Moçambique de 1975, aprovada logo que o país se tornou independente, é reconhecida a igualdade entre homens e mulheres. No ano de 2007, foi aprovada, através da Resolução número 19/2007, a Política de Gênero e Estratégia para sua Implementação, que traça diretrizes para orientação de ações que elevem a condição da mulher moçambicana a um estado de maior igualdade de gênero. No entanto, embora Moçambique tenha uma história progressista em relação aos demais países africanos, no sentido da busca por implementar políticas de igualdade de gênero, quando se trata de dados, o país ainda conserva alguns dos piores indicadores relacionados ao gênero. Na prática, grande parte das mulheres moçambicanas segue enfrentando empecilhos como: casamento e gravidez precoces, condições precárias de educação e saúde e dificuldade de acesso ao mercado de trabalho formal. Estes fatores, de origens socioculturais, resultam em indicadores preocupantes (tabela 01), que ilustram a situação da mulher moçambicana como figura vulnerável e subalterna à figura masculina.

Tabela 01: Índice de desenvolvimento de gênero

\begin{tabular}{|c|cc|c|c|c|c|}
\hline ESPERANÇA DE VIDA & $\begin{array}{c}\text { ANOS DE } \\
\text { ESCOLARIDADE } \\
\text { ESPERADOS }\end{array}$ & $\begin{array}{c}\text { MÉDIA DE ANOS DE } \\
\text { ESCOLARIDADE }\end{array}$ & $\begin{array}{c}\text { RENDIMENTO } \\
\text { NACIONAL BRUTO } \\
\text { (PER CAPITA) }\end{array}$ & $\begin{array}{c}\text { ÍNDICE DE } \\
\text { DESENVOLVIMENTO } \\
\text { HUMANO }\end{array}$ \\
\hline $\begin{array}{c}\text { MULHERES HOMENS } \\
56,5\end{array} \quad 53,6$ & $\begin{array}{c}\text { MULHERES HOMENS } \\
8,8\end{array} \quad 9,8$ & MULHERES HOMENS & MULHERES HOMENS & MULHERES HOMENS \\
\hline
\end{tabular}

Fonte: Moçambique, 2016, a partir de dados de PNUD Human Development Report (2015). 
As diferenças regionais também acarretam diferentes níveis de desigualdade de gênero ao longo do território moçambicano. Na tabela 02 , é possível visualizar a diferença entre as taxas de analfabetismo de acordo com a província do país. As altas taxas para as províncias de Niassa e Nampula, ambas localizadas ao norte, assim como a discrepância entre as taxas entre a população rural e urbana, revelam a grande desigualdade regional relativa às condições de educação.

Tabela 02: Taxa de analfabetismo por sexo e província (dados de 2014 e 2015)

\begin{tabular}{|c|r|c|c|}
\hline & \multicolumn{1}{|l|}{ TOTAL } & HOMENS & MULHERES \\
\hline URBANA & 23,1 & 14 & 31,4 \\
\hline RURAL & 56,6 & 39,1 & 71,6 \\
\hline Niassa & 58 & 42,6 & 72,4 \\
\hline Nampula & 56 & 40,5 & 71,2 \\
\hline Zambézia & 53,9 & 34,3 & 71,9 \\
\hline Gaza & 32,4 & 19,3 & 40,7 \\
\hline Maputo & 9,5 & 4,7 & 13,7 \\
\hline
\end{tabular}

Fonte: Moçambique, 2016, a partir de dados de IOF, 2014-2015.

Na região sul, a urbanização tem exercido um papel importante na mudança de padrões socioculturais e do estilo de vida da população, abrindo novos caminhos para os homens e especialmente para as mulheres (TVEDEN et al, 2010). A participação das mulheres na economia formal é mais comum e bem aceita, e rapazes e moças têm acessos semelhantes à educação. Nesse contexto, a mulher encontra, também, maiores possibilidades de se emancipar dentro do ambiente familiar, se tornando, muitas vezes, a chefe de família.

No entanto, é importante apontar que, mesmo dentro do contexto urbano, há grandes diferenciações ao analisar o padrão de vida das mulheres. Aquelas de classes sociais mais baixas se encontram, muitas vezes, em graus de vulnerabilidade ainda inferiores aos das mulheres do campo. A vida degradante dos pobres urbanos traz a essas mulheres ainda menos autonomia, reforçando a relação de dependência do homem. Dessa forma, analisar a pobreza se torna central também para compreender certas dimensões do tema de gênero.

Autores como Tveden et al. (2010) e Casimiro (2014) criticam as políticas de gênero, que não têm conseguido chegar a estas situações mais críticas do país, tanto as áreas rurais quanto áreas urbanas de maior pobreza. Embora reconheça a importância de mudanças, como 
a notável e ampla presença de mulheres no quadro político do país ${ }^{3}$, Casimiro (2014) defende que, mesmo presentes na política, as mulheres seguem silenciadas por um reflexo social e histórico. Este fato isolado, por si só, não trará mudanças efetivas, e também é necessário

democratizar os espaços 'públicos' onde a 'política' tem lugar. É fundamental reconhecer e valorizar as diversas formas que a participação da mulher assume, os silenciamentos sobre seus saberes, conhecimentos e práticas, as suas percepções e representações, devolvendo-lhes o necessário protagonismo (...) (CASIMIRO, 2014, p. 31)

\section{Tabela 03: Características do mercado de trabalho em Moçambique}

\begin{tabular}{|l|c|c|}
\hline DESCRIÇÃo & MULHERES (\%) & HOMENS (\%) \\
\hline Empregadas na altura do IDS & 39,4 & 82,3 \\
\hline Sem emprego na altura do IDS & 7,3 & 4,9 \\
\hline Sem emprego nos últimos 12 meses antes do IDS & 53,3 & 12,7 \\
\hline Ocupação: setor da agricultura & $\begin{array}{c}63,1(27,5 \text { urbana / } \\
80,8 \text { rural) }\end{array}$ & $\begin{array}{c}43 \text { (14,2 urbana / 56,1 } \\
\text { rural) }\end{array}$ \\
\hline Ocupação: profissional ou técnica administrativa & 5,3 & 6,5 \\
\hline Ocupação: vendas e serviços & $24(42,2$ urbana / 14,9 & $21,8(28,3$ urbana / \\
\hline rural) & 44 & rural) \\
\hline Empregados não remunerados (não especificado) & 17,6 & 31 \\
\hline Empregado por outrem: setor agrícola & 82,4 & N/A \\
\hline Auto-emprego: setor agrícola & 40,7 & N/A \\
\hline Empregado por outrem: setor não agrícola & 59,3 & N/A \\
\hline Auto-emprego: setor não agrícola & N/A \\
\hline
\end{tabular}

Fonte: Moçambique (2016), a partir de dados do Inquérito Demográfico e de Saúde (2011)

De forma geral, a taxa de participação da força de trabalho feminina é de 82,5\%, superior à dos homens moçambicanos, à média da África subsaariana e de outros países de baixo IDH (UNFPA, 2017). Exerce bastante influência neste dado a prática de atividades agrícolas, entre as quais se revela a predominância feminina em relação à participação masculina, segundo a tabela 03. É importante salientar, no entanto, que as atividades econômicas desempenhadas pelas mulheres moçambicanas, inclusive a agricultura, são, em sua maioria, atividades informais e extremamente associadas ao padrão tradicional da mulher dona

\footnotetext{
${ }^{3}$ Moçambique se destaca entre os países africanos e mundialmente pela participação feminina nos espaços políticos de tomadas de decisão do Estado. Para MOÇAMBIQUE (2016), isto se deve ao sistema de cotas implantado, assim como o aumento do acesso à escolaridade e da conscientização em geral para a importância da participação da mulher.
} 
de casa, e muitas vezes acaba reforçando o lugar da mulher moçambicana como o ambiente do lar.

Tabela 04: Porcentagem de casamentos antes de 15 e 18 anos de idade, por sexo e região

\begin{tabular}{|l|c|c|c|}
\hline \multirow{2}{*}{} & \multicolumn{2}{|c|}{ FEMININO } & MASCULINO \\
\cline { 2 - 4 } & abaixo de 15 & abaixo de 18 & abaixo de 18 \\
\hline TOTAL & 14,3 & 48,2 & 8,7 \\
\hline Urbano & 11,5 & 36,1 & 4,8 \\
\hline Rural & 16,1 & 55,7 & 11,8 \\
\hline
\end{tabular}

Fonte: Moçambique (2016), a partir do IDS (2011)

Outras problemáticas relativas ao gênero em Moçambique são as altas taxas de fecundidade e natalidade, que estão bastante relacionadas à gravidez e ao casamento precoces. Segundo Moçambique (2016), 40\% das mulheres que possuem filhos tiveram seu primeiro filho antes dos 17 anos, e $8 \%$ antes mesmo dos 15 anos. Segue-se ainda que 48,2\% das mulheres se casaram com menos de 18 anos, sendo $14 \%$ antes dos 15 anos, como mostra a tabela 04 . As condições precárias da saúde pública levam também a elevadas taxas de mortalidade materna, revelando, mais uma vez, a vulnerabilidade das mães moçambicanas. (MOÇAMBIQUE, 2018; TVEDEN et al, 2010)

O casamento e a gravidez precoces costumam interromper ou até mesmo inviabilizar o acesso das meninas moçambicanas à educação escolar, uma vez que direcionam a mulher moçambicana para uma dedicação quase completa à sua nova família. A desigualdade no acesso à educação é evidente quando destacamos as médias de escolaridade por sexo: enquanto a média nacional de escolaridade feminina é de 2,4 anos, a masculina é de 4,3 anos. Ademais, a taxa de alfabetização feminina é de 45,37\%, enquanto a masculina é de 73,26\% (UNESCO, 2016).

Sen (1999) determina que esta condição de vida irá influenciar não apenas nas escolhas de vida das mulheres, mas também nas possibilidades de vida dos seus familiares, principalmente das filhas mulheres. Estas características sociais, baseadas na desigualdade de gênero, tendem a ser perpetuadas ao longo das gerações seguintes, o que acabará por trazer o mesmo tipo de vida às filhas, meninas e jovens.

Portanto, a dedicação da mulher moçambicana à família e aos filhos desde tão jovem acaba limitando suas escolhas de vida, tanto dentro do ambiente familiar, onde se subordina à 
figura do homem, quanto na sua vida profissional, que, quando existente, costuma se dirigir para o trabalho agrícola, ligado, mais uma vez, aos cuidados e à manutenção do lar.

\section{DESENVOLVIMENTO COMO LIBERDADE E MULHER COMO AGENTE DE MUDANÇA SOCIAL}

\section{A noção de desenvolvimento de Amartya Sen}

Para Amartya Sen (1999), o desenvolvimento consiste, de forma sintética, na superação dos atuais problemas da sociedade. Estes problemas devem ser observados numa esfera mais ampla, que transcende o indivíduo, o impedindo de exercer suas escolhas de vida, de acordo com suas aspirações e desejos próprios. Neste sentido, para o autor, não é possível separar a condição individual do sujeito (no caso estudado, a mulher moçambicana) e as disposições sociais que regem a sua vida em coletivo. Portanto, o desenvolvimento pleno, contendo suas diversas facetas (social, econômica, política), está relacionado com a expansão das capacidades individuais, ou, em outras palavras, à "eliminação das privações de liberdade que limitam as escolhas e oportunidades das pessoas de exercer sua condição de agentes” (SEN, 1999, p. 10).

Considerando que, em grande parte dos países do mundo, a desigualdade de gênero tem privado a mulher de exercer suas escolhas e ameaçado sua liberdade, naturalmente a discussão sobre gênero toma um lugar central dentro dos debates sobre o desenvolvimento territorial e especificamente do desenvolvimento como liberdade seniano. Nesse aspecto, a equidade de gênero tem sido tema extremamente pautado por agências e organizações internacionais, como a UNESCO, ONU e o Banco Mundial. Estas organizações orientam políticas de desenvolvimento através da busca pela equidade de gênero, visando temas como a inserção da mulher no mercado de trabalho, a prevenção à violência sexual e à gravidez precoce e a alfabetização feminina, iniciativas que dialogam com a perspectiva de Sen. (BANCO MUNDIAL, 2012)

\section{A mulher como agente de mudança nos países subdesenvolvidos}

Assim, é importante que, dentro dos atuais debates sobre gênero, se supere a antiga discussão das questões de gênero exclusivamente relativas à situação de bem-estar que a mulher usufrui, e que se enfoque na efetiva condição de agente da mulher dentro da sociedade em que vive. Sen (1999) faz a definição de agente como "alguém que age e ocasiona mudança e cujas realizações podem ser julgadas de acordo com seus próprios valores e objetivos” (SEN, 1999, 
p. 33) Esta definição contrapõe a ideia de que os indivíduos se desenvolvem plenamente ao serem receptores passivos de benefícios ou assistências, e associa o desenvolvimento real à capacidade individual de autorrealização, que é influenciada por oportunidades econômicas, liberdades políticas, disposições sociais, entre diversos fatores.

Contextualizando o objeto de estudo escolhido, a mulher em Moçambique, compreendese que o desenvolvimento, na perspectiva de Sen, para o recorte escolhido, consiste no empoderamento desta mulher, no sentido de obtenção do poder de escolher sobre seu próprio destino.

O poder de escolher, de ter autonomia, equaciona a possibilidade ou não que as mulheres têm de tomada de decisões, enquanto mulheres, com direitos e deveres, na família, na comunidade, ou sociedade. Define, por isso, um caminho próprio, e não imposto, que reconhece e respeite os direitos das mulheres no seu processo de procura de melhores condições de vida para si, para as suas famílias ou comunidades. (CASIMIRO, 2014, p.19)

Sob este ponto de vista, para que o desenvolvimento da mulher e da sociedade em sua totalidade ocorra de forma integral, não bastam políticas contra a violência sexual, que asseguram bons tratos às mulheres; é necessário garantir a elas uma série de outros acessos importantes: formação de qualidade, oportunidades de emprego, salários justos, educação sexual e reprodutiva, presença nos espaços políticos de decisão, entre outros aspectos. Quando todo este arranjo complexo de capacidades e oportunidades se desenhar, somente então a mulher poderá atuar na sua condição de agente de forma plena.

As mulheres que alcançam maior controle dos gastos domésticos e das decisões familiares, por exemplo, frequentemente escolhem investir melhor nas condições de educação e criação dos filhos, seja através da aquisição de alimentos de melhor qualidade, do investimento na escolaridade das crianças de melhor qualidade (especialmente das crianças do sexo feminino), ou em reformas para o melhoramento do ambiente do lar. No entanto, para que as mulheres alcancem o maior controle dos gastos e decisões domésticas, é necessário que as mães adquiram maiores níveis de escolaridade e melhores oportunidades de emprego. (BANCO MUNDIAL, 2012)

Os benefícios ocasionados pela maior participação das mulheres na esfera pública e institucional também são notáveis. Sen (1999) menciona a importância da participação feminina na elaboração de políticas sociais e ambientais, mediante a tendência que as mulheres têm de priorizar o bem-estar coletivo. Além disso, mulheres em posições de decisão poderão fortalecer a pauta da equidade de gênero, buscando ações concretas que favoreçam as mulheres. 
Melhores políticas de saúde para as mulheres ocasionam menores índices de mortalidade e desnutrição infantil. (SEN, 1999)

Algumas ações governamentais em países em desenvolvimento através de programas e políticas sociais podem ser bons exemplos de incentivos a um maior poder da mulher no ambiente doméstico. No Brasil, por exemplo, 93\% dos titulares do Programa Bolsa Família ${ }^{4}$ são mulheres ${ }^{5}$. No Programa Minha Casa Minha Vida ${ }^{6}$, a lei 11.977 , que dispõe sobre o Programa, determina que as mulheres devem ser priorizadas no registro dos imóveis como chefes de família. Nos dois casos apontados, o melhoramento das condições de vida em família e a maior autonomia financeira feminina são uma via de mão dupla.

Assim, é possível compreender de que forma a ampliação das capacidades de realização da mulher, ou a expansão da sua condição de agente, são convertidos em benefícios para a mulher e sua família, o que, por sua vez, em larga escala, virá a beneficiar toda uma sociedade, um país. Em países em desenvolvimento, subdesenvolvidos ou com baixos índices e indicadores sociais, o melhoramento das condições de vida das mulheres é chave vital; sem a busca pela equidade de gênero, o desenvolvimento social nunca se dará de forma absoluta.

\section{O empoderamento da mulher moçambicana através do xitike}

Conforme mencionado, a pobreza, a má distribuição da riqueza são realidades muito presentes em Moçambique, e fazem com que grande parte da população viva num estado de crise econômica constante. A fragilidade econômica do país e o estado de pobreza da população servem como base, muitas vezes, para uma visão externa de condolência, no qual o povo moçambicano é visto unicamente como um povo reprimido, e raramente como agentes transformadores e sujeitos carregados de potencial, responsáveis pelo seu próprio desenvolvimento.

No entanto, de forma bastante natural e espontânea, as populações destes países atuam em busca de resistir às dificuldades a elas impostas e melhorar suas condições de vida. Para isso, utilizam-se de saberes e práticas populares, por vezes adaptadas às novas tecnologias e aos

\footnotetext{
${ }^{4}$ O Programa Bolsa Família é um programa governamental brasileiro de transferência de renda a famílias pobres. $\mathrm{O}$ auxílio financeiro só é distribuído às famílias sob as seguintes condições: os fillhos que possuem entre 6 e 17 anos devem frequentar a escola; as mulheres grávidas da família devem receber acompanhamento médico; as crianças e mulheres grávidas devem manter suas vacinações em dia.

5 Ver http://www.brasil.gov.br/cidadania-e-justica/2013/09/mulheres-representarm-93-da-titularidade-do-bolsafamilia

${ }^{6}$ O Programa Minha Casa Minha Vida é um programa governamental brasileiro lançado em 2009 que subsidia a obtenção de casa ou apartamento próprio para a população de baixa e média renda.
} 
costumes contemporâneos, num processo de reinvenção de suas formas de vida. Dentro destas práticas, algumas das mais comuns são espécies de associações solidárias e rotativas de créditos e poupança, com características muito próprias e peculiares. Estas atividades, embora estejam inseridas numa economia informal e, por essa razão, possam ser consideradas como marginais, têm sido fundamentais para garantir a continuidade e a sobrevivência de alguns grupos socialmente vulneráveis, principalmente aqueles compostos por mulheres. (CASIMIRO, 2014; TRINDADE, 2015)

Atividades de base associativa assentam-se, segundo Casimiro (2014), na vontade de seus membros, baseados na solidariedade e com objetivo final o bem comum. Parte de uma noção de coletividade e de cuidado mútuo, na qual os integrantes se oferecem enquanto indivíduos ativos na construção desse bem comum.

A participação das mulheres em associações por si organizadas permite-lhes adquirir não apenas recursos materiais - terra, trabalho e capital - mas também recursos políticos ou sociais acedendo aos mecanismos que lhes assegurem a continuidade de acesso aos recursos. (CASIMIRO, 2014, p. 14)

Nesse sentido, o xitike $e^{7}$ surge como uma destas práticas socioeconômicas carregadas de potencial, atuando como importante mecanismo de desenvolvimento local econômico. Seu funcionamento é semelhante à poupança, favorecendo as trocas (materiais e imateriais) e objetivando "a aquisição de bens, produtos e serviços que de outra maneira não seriam acessíveis a determinado grupo de pessoas mediante a escassez da moeda com que vivem" (TRINDADE, 2015, p. 2)

A base do xitike é um grupo de pessoas formado por parentes, amigos, colegas de trabalho ou simplesmente pessoas que possuem algum vínculo mais pessoal. Este grupo se reúne em uma periodicidade determinada coletivamente. Na ocasião da reunião, cada integrante faz uma contribuição monetária de um valor também estabelecido pela coletividade; e, a cada reunião, um integrante específico do grupo é sorteado ou escolhido para receber a soma total das contribuições. A soma passa a ser de responsabilidade do integrante sorteado, que a utilizará como parte de um investimento pessoal. Dessa maneira, em sistema rotativo, a cada mês um dos integrantes do grupo tem a oportunidade de receber a quantia. Isto propicia que os membros do grupo realizem um planejamento pessoal de gastos a médio ou longo prazo, pois são

\footnotetext{
${ }^{7}$ Alguns autores utilizam a denominação xitiki, a forma tradicional de escrita dos povos moçambicanos, ou, ainda, "xitique", a forma traduzida para os portugueses. No entanto, optou-se pela denominação xitike, seguindo o sistema de Padronização da Ortografia das Línguas Bantu de Moçambique.
} 
"forçados" a conter gastos e a economizar mensalmente por um período de tempo, até que chegue o momento de receber o seu xitike.

Por vezes o sistema econômico do xitike acaba por apresentar maiores vantagens econômicas aos usuários do que, por exemplo, possuir uma conta bancária ou uma poupança, pois o xitike não tem juros e nem exige formalidades jurídicas. Sendo o destino do dinheiro do xitike um investimento pessoal do ganhador, é muito comum que se discuta em grupo previamente quais os fins específicos para os quais cada integrante pretende usar seu xitike. Neste sentido, não apenas o funcionamento do grupo é coletivamente organizado, mas também a gestão dos recursos. Destinos comuns para o xitike são a compra de terrenos, a construção e reforma de casas e o investimento na educação dos filhos. (CUNHA, 2014; TRINDADE, 2015)

Embora seja habitualmente traduzido como "poupança", a palavra xitike acaba adquirindo diversos outros significados, devido à sua dimensão de ajuda mútua e solidariedade. Na aproximação com os sujeitos, Trindade (2015) aponta que a mera tradução de xitike como crédito rotativo ou poupança é limitada e insuficiente para compreender o universo dessa prática. Para a autora, o xitike possui caráter multidimensional, e está intimamente ligado ao fortalecimento dos laços de amizade ou de família, os quais, dentro da prática do xitike, se misturam bastante. Nesse sentido, o compromisso do xitike se torna também um compromisso afetivo.

Mesmo que não haja restrição para a prática entre homens e mulheres, Trindade (2015) ressalta que, em geral, acaba por se tratar de uma prática predominantemente feminina, pois são geralmente as mulheres as mais interessadas na organização e na manutenção do grupo. Embora muitas vezes os homens façam parte do xitike, é comum que não mantenham sua assiduidade na participação das reuniões.

Para Cunha (2014) e Trindade (2015), o xitike contribui com uma maior autonomia financeira da mulher, e portanto com o aumento da sua capacidade de incidir sobre as decisões familiares. $\mathrm{O}$ xitike contribui igualmente com a coesão social através da afirmação da identidade pessoal e comunitária. O fortalecimento do grupo é também o fortalecimento das mulheres individualmente, já que as reuniões do xitike se transformam em espaço de troca e de conversa entre elas. A prática do xitike não é apenas uma prática de poupança e crédito rotativo, uma estratégia de sobrevivência, mas também um importante espaço de convivência, de trocas e de manutenção das redes de ajuda entre mulheres. 


\section{CONSIDERAÇÕES FINAIS}

A partir da abordagem do desenvolvimento territorial, que percebe o desenvolvimento através das capacidades locais e individuais, chega-se à compreensão de que analisar a situação da mulher dentro do contexto socioeconômico do país é fundamental na interpretação do nível de desenvolvimento do país. $O$ discurso da igualdade de gênero para o desenvolvimento tem ganhado muita visibilidade, sobretudo no âmbito das políticas internacionais para o desenvolvimento. Como exemplo, tem-se o documento do Banco Mundial (2012), que enfatiza os dois tipos de importância desse processo: a importância "natural" e a importância instrumental. Enquanto a primeira importância preza pela questão destacando-a enquanto direito fundamental, a segunda ressalta os ganhos econômicos que podem ser obtidos através da equidade de gênero.

Em países em desenvolvimento, evidentemente, a equidade de gênero ainda encontra muitos desafios. O contexto moçambicano ainda apresenta uma grande diferença entre as capacidades e liberdades potenciais de homens e mulheres, o que acarreta em oportunidades bastante diferentes para os dois gêneros. Embora grande parte da economia do país seja movimentada pelas mulheres, estas ainda estão muito limitadas ao ambiente do lar e das atividades domésticas. Os altos índices de casamento e gravidez precoce, associados aos baixos índices de escolaridade e alfabetização femininos revelam que as mulheres moçambicanas ainda possuem pouca liberdade para decidir sobre seus futuros pessoais e profissionais, e mais, sobre o destino de suas crianças e sua família. (UNESCO, 2016; UNFPA, 2017; INE, 2017) O Banco Mundial (2012) e a Unesco (2016) orientam que a valorização da mulher deve ocorrer através de ações de prevenção da violência sexual, promoção de saúde sexual reprodutiva e serviços de planejamento familiar, programas de alfabetização sensíveis ao gênero, além da garantia de salários igualitários para homens e mulheres.

O trabalho apresenta o xitike como exemplo de prática endógena, bastante típica entre grupos de mulheres moçambicanas, e a destaca como prática social que tem ocasionado a expansão das liberdades individuais das mulheres. As possibilidades de atuação da mulher como agente de mudança social também são ampliadas, já que ela ganha, através do xitike, mais autonomia pessoal e financeira, cujos resultados serão percebidos na escala familiar. Dessa forma, ela tem mais liberdade para atuar em favor do futuro dos filhos, investindo na sua escolaridade, saúde ou mesmo no ambiente familiar. Isto corrobora com a relação que Sen (1999) cria entre o aumento de capacidades econômicas da mulher e a melhora da qualidade de vida da família e dos filhos. 
Pela ótica do desenvolvimento territorial em Moçambique, políticas, ações e práticas como a do xitike, que têm como consequência a valorização da mulher, certamente ocasionarão a diminuição de alguns índices do país que, atualmente, contribuem com a manutenção da pobreza. Algumas possíveis mudanças nos índices socioeconômicos ocasionadas pelo maior controle da mulher sobre o planejamento familiar seriam: a diminuição do número de gravidez precoce, diminuição nas taxas de fecundidade e de natalidade, levando a um maior equilíbrio na distribuição da idade da população, que hoje é predominantemente jovem; o aumento do PIB per capita; melhor escolaridade das crianças e jovens; e isto, por sua vez, poderá oferecer a uma vasta quantidade de crianças melhores oportunidades de emprego e geração de renda futuramente.

\section{REFERÊNCIAS}

\section{BANCO MUNDIAL. Igualdade de Gênero e Desenvolvimento: Relatório sobre o} Desenvolvimento Mundial de 2012. Washington: Banco Mundial, 2012. Disponível em: < http://siteresources.worldbank.org/INTWDR2012/Resources/77781051299699968583/7786210-1315936231894/Overview-Portuguese.pdf>. Acesso em: 28 de março de 2019.

BRANDÃO, Carlos. Desenvolvimento, Territórios e Escalas Espaciais: levar na devida conta as contribuições da economia política e da geografia crítica para construir a abordagem interdisciplinar In: RIBEIRO, Maria Teresa Franco; MILANI, Carlos R. S. (orgs.). Compreendendo a complexidade socioespacial contemporânea: o território como categoria de diálogo interdisciplinar. Salvador, Editora da UFBA. 2008. p. 115 - 150.

\section{CASIMIRO, Isabel Maria. "Algumas Experiências de Mulheres em Actividades}

Geradoras de Rendimentos: Estudos de caso em 4 distritos de Moçambique". Revista Estudos Moçambicanos, v.23, p. 7-36, mar., 2014. Disponível em: <http://www.mozambiquehistory.net/periodicals/estud_moc/23/casimiro_em_23.pdf>. Acesso em: 28 de março de 2019.

CORRÊA, Vanessa Petrelli. "Desenvolvimento territorial e a implantação de políticas públicas brasileiras vinculadas a esta perspectiva". Boletim Regional, Urbano e Ambiental - IPEA. nº 3, Dezembro, 2009. Disponível em: < http://www.ipea.gov.br/portal/index.php?option=com_content\&view=article\&id=1574\&Itemi d=7> Acesso em: 28 de março de 2019.

CUNHA, Teresa. "O xitique delas. Um ensaio feminista pós-colonial sobre o xitique em Moçambique” In: XII CONLAB 1. Congresso da Associação Internacional de Ciências Sociais e Humanas em Língua Portuguesa, 2014. Disponível em: < https://www.academia.edu/24378529/O_Xitique_Delas._Um_ensaio_feminista_póscolonial_sobre_o_xitique_em_Moçambique>. Acesso em: 28 de março de 2019. 
HAESBAERT, Rogério. Dos Múltiplos Territórios à Multiterritorialidade. Porto Alegre: PETGEO/UFRGS, setembro de 2004. Disponível em: 〈www.ufrgs.br/petgea/Artigo/rh.pdf $>$. Acesso em: 18 de outubro de 2018.

JEAN, Bruno. "Le développement territorial durable: une nouvelle approche de développement rural”. Desenvolvimento e Meio Ambiente, v. 33, p. 115-127, abr. 2015.

LEGOUTÉ, Jean Ronald. "Définir Le Développement: Historique et Dimensions d'un Concept Plurivoque." Économie Politique Internacionale: Cachiers de recherche. Université de Québec à Montréal. v. 1, n 1. fev, 2001. Disponível em:

$<$ https://pt.scribd.com/document/168529385/Definir-Le-Developpement-Historique-etDimensions-Dun-concept-plurivoque>. Acesso em: 28 de março de 2019.

MOÇAMBIQUE. Ministério do Gênero, Criança e Ação Social. Perfil de Gênero de Moçambique. Maputo, 2016. Disponível em: <

https://eeas.europa.eu/sites/eeas/files/perfil_de_genero_de_mocambique.pdf >. Acesso em: 28 de março de 2019.

INE - Instituto Nacional de Estatística. Dados definitivos do IV

Recenseamento Geral da População e Habitação. Maputo: Instituto Nacional de Estatística, 2017.

Política de Gênero e Estratégia da sua Implementação. Maputo, 2018.

MOURA, Joana Tereza Vaz de; MOREIRA, Ivaldo Sousa. “A abordagem territorial do desenvolvimento a partir da perspectiva relacional: uma proposta teórica preliminar." REDES - Rev. Des. Regional, v. 19, n. 1, p. 58 - 73, jan/abr, 2014. Disponível em: < https://online.unisc.br/seer/index.php/redes/article/view/2454>. Acesso em: 28 de março de 2019.

PIRES, Elson L.S. "As lógicas territoriais do desenvolvimento: diversidades e regulação." Interações - Revista Internacional de Desenvolvimento Local, n.8, p.155-163, set., 2007.

PRADO, Fernando Correa. "Questões sobre o desenvolvimento." Revista da Sociedade Brasileira Economia Política, n. 45, p. 68-86, out.-dez., 2016.

SANTOS, Elinado Leal et al. Desenvolvimento, um conceito multidimensional. DRd Desenvolvimento Regional em debate. Revista Eletrônica do Programa de Mestrado em Desenvolvimento Regional da Universidade de Contestado, Brasil, Ano 2, n. 1, jul. 2012. Disponível em: http://www.periodicos.unc.br/index.php/drd/article/view/215 Acesso em: 11 de novembro de 2018.

SANTOS, Milton. O retorno do território. In: SANTOS, Milton; SILVEIRA, Maria Laura; SOUZA, Maria Adélia A. de. (Org.) Território: Globalização e Fragmentação. São Paulo: HUCITEC. 1998. p. $15-20$.

SEN, Amartya. Desenvolvimento como liberdade. São Paulo: Companhia das Letras, 2000.

TRINDADE, Catarina Casimiro. "Xitiki é compromisso": os sentidos de uma prática de sociabilidade na cidade de Maputo, Moçambique. 2015. Dissertação (Mestrado em 
Antropologia Social) - Instituto de Filosofia e Ciências Humanas, Universidade Estadual de Campinas - SP. Disponível em: <

http://repositorio.unicamp.br/jspui/handle/REPOSIP/279632>. Acesso em: 28 de março de 2019.

TVEDTEN, I.; PAULO, M.; TUOMINEN, M. “Género e pobreza em Moçambique” Revista CMI Resumo, v. 9, n. 6. p. 1-4, out., 2010. Disponível em: < https://www.cmi.no/publications/3813-genero-e-pobreza-em-moambique>. Acesso em: 28 de março de 2019.

UNFPA. Mundos distantes: saúde reprodutiva e direitos numa era de desigualdades. Maputo: UFNPA, 2017.

UNESCO. Relatório Anual 2016. Unesco, 2016.

Recebido em Abril de 2019

Aprovado em Junho de 2019

Publicado em Agosto de 2019 